\title{
Local intra-arterial fibrinolysis for acute occlusion of the central retinal artery: a meta-analysis of the published data
}

\author{
S Beatty, K G Au Eong
}

\begin{abstract}
Backgroundlaim-Central retinal artery occlusion (CRAO) is typically associated with a poor visual outcome. Several favourable reports of local intra-arterial fibrinolysis (LIF), which involves the superselective administration of a thrombolytic agent directly into the ophthalmic artery, have appeared in the recent literature. The aim of this study was to critically appraise these studies in a collective fashion.

Methods-A meta-analysis was performed of all the published literature germane to LIF in cases of CRAO.

Results-Of the 16 studies identified, all were retrospective and non-randomised. After correction for data duplication, the results of LIF in 100 patients can be reported. A final acuity of $6 / 6$ or better was seen in $14 \%$ of patients following LIF, and a visual result of $6 / 12$ or better was seen in $27 \%$ of subjects. A poor final acuity of $3 / 60$ or worse was seen in $\mathbf{6 0 . 6 \%}$ of eyes treated with local intra-arterial fibrinolysis. These results compare favourably with conventional forms of therapy. Potentially serious complications were seen in four patients, but no patient suffered a permanent neurological deficit.

Conclusion-The results of this study suggest that there may be a marginal visual benefit associated with LIF compared with conventional management of CRAO. However, the methodology of the cited
\end{abstract}

studies was often unsatisfactory, and a randomised controlled trial of LIF in cases of CRAO is justified. Outside of a randomised clinical trial, the use of superselective fibrinolytic therapy for CRAO cannot be recommended on the basis of current evidence.

(Br f Ophthalmol 2000;84:914-916)

Central retinal artery occlusion (CRAO) is associated with a poor visual prognosis, and aggressive management with ocular massage, anterior chamber paracentesis, and carbogen therapy does not appear to improve the outcome. ${ }^{12}$ These considerations have motivated the use of catheter administered, local intra-arterial fibrinolysis (LIF) for CRAO, of which there are several encouraging reports in the literature. We have performed a metaanalysis of the published data in order to investigate whether we should be offering LIF to our patients presenting with acute occlusive events of the retinal arterial circulation.

\section{Methods}

Sixteen reports of intra-arterial fibrinolytic therapy for CRAO were identified in the published literature, ${ }^{3-18}$ (Table 1), and covert duplicate use of data was found in three of these papers ${ }^{368}$ and acknowledged duplication in a further two papers, ${ }^{70}$ a problem commonly encountered in meta-analyses. ${ }^{19}$ Therefore, only the most recent and complete series reported by these investigators were included

Table 1 Studies and review articles relating to fibrinolytic therapy in central retinal artery occlusion

Academic Department of Ophthalmology, Manchester Royal Eye

Hospital

S Beatty

K G Au Eong

Correspondence to:

S Beatty, Medical Retina

Unit, Department of Clinical

Ophthalmology, Moorfields

Eye Hospital, City Road,

London EC1V 2PD

stephen@

stiofanbetagh.demon.co.uk

Accepted for publication 16 March 2000

\begin{tabular}{lcll}
\hline Author, year & Number of subjects & Fibrinolytic agent & Comment \\
\hline Richard et al, $1999^{18}$ & 46 & rt-PA & \\
Weill et al, $1998^{16}$ & 7 & Urokinase & \\
Wirostko et al, $1998^{15}$ & 1 & Urokinase & Case report \\
Weber et al, $1998^{5}$ & 15 & Urokinase & \\
Annonier et al, $1988^{7}$ & 5 & Urokinase & Contains data also used in reference 10 \\
Schumacher et al, $1993^{6}$ & 23 & Urokinase (n=18) & \\
& & rt-PA (n=5) & \\
Vulpius et al, $1996^{9}$ & 9 & rt-PA & \\
Annonier et al, $1984^{10}$ & 2 & Urokinase & Contains data also used in reference 7 \\
Mach et al, $1992^{17}$ & 1 & Urokinase & Case report \\
Coscas et al, $1970^{12}$ & 1 & Streptokinase & Intravenous administration \\
Ma et al, $1996^{4}$ & 4 & Urokinase & Insufficient data for comment \\
Brassel et al, $1993^{14}$ & NA & Review article \\
Schmidt et al, $1992^{3}$ & 14 & Urokinase & Contains data also used in reference 6 \\
Van Cauwenberge, $1993^{11}$ & NA & NA & Review article \\
Schumacher et al, $1991^{8}$ & 6 & Urokinase & Contains data also used in reference 6 \\
Turmer et al, $1993^{13}$ & NA & NA & Animal study \\
\hline
\end{tabular}


in the analysis. Although we do comment on case reports and small series (less than five subjects), the meta-analysis is confined to the five studies involving seven or more subjects.

The technique of LIF varied between studies, but in all cases the fibrinolytic agent was injected by hand through a coaxial catheter system placed in the ophthalmic artery. The dose was typically determined by the need to avoid reaching therapeutic systemic levels, and by clinical response as evaluated by repeated ophthalmoscopy, confrontational perimetry, and acuity testing during the procedure. LIF was always followed by heparinisation for a period of 2-3 days.

\section{Results}

The visual acuities at presentation were statistically similar for the studies that satisfied the inclusion criteria $\left(\chi^{2} 19.89 ; \mathrm{p}=0.07\right)$, and the original data were therefore combined and analysed as a single file comprising 100 subjects with CRAO treated with local intraarterial fibrinolytic therapy. Ages ranged from 19 to 87 years, with a mean (SD) of 61.1 (13.9), and the male:female ratio was 71:29. The mean delay between the onset of symptoms and the administration of fibrinolytic therapy was 11.6 (8.7) hours (range 3-60 hours). Fibrinolytic agents used included urokinase $(42 ; 42 \%)$ and recombinant tissue plasminogen activator (rt-PA) (58;58\%). All patients had a Snellen visual acuity of $6 / 60$ or worse at presentation, with the exception of two who had acuities of $6 / 18$ and $6 / 9$

Final visual acuities ranged from perception of light (PL) to $6 / 6$. Of the 100 subjects, 14 achieved a final acuity of $6 / 6$ or better, 27 achieved a final acuity of $6 / 12$ or better, and 37 achieved a final vision of $6 / 60$ or better (Fig 1 ). These results represent a mean improvement in acuity of three (3.05) Snellen lines. Changes in acuity were unrelated to the delay between

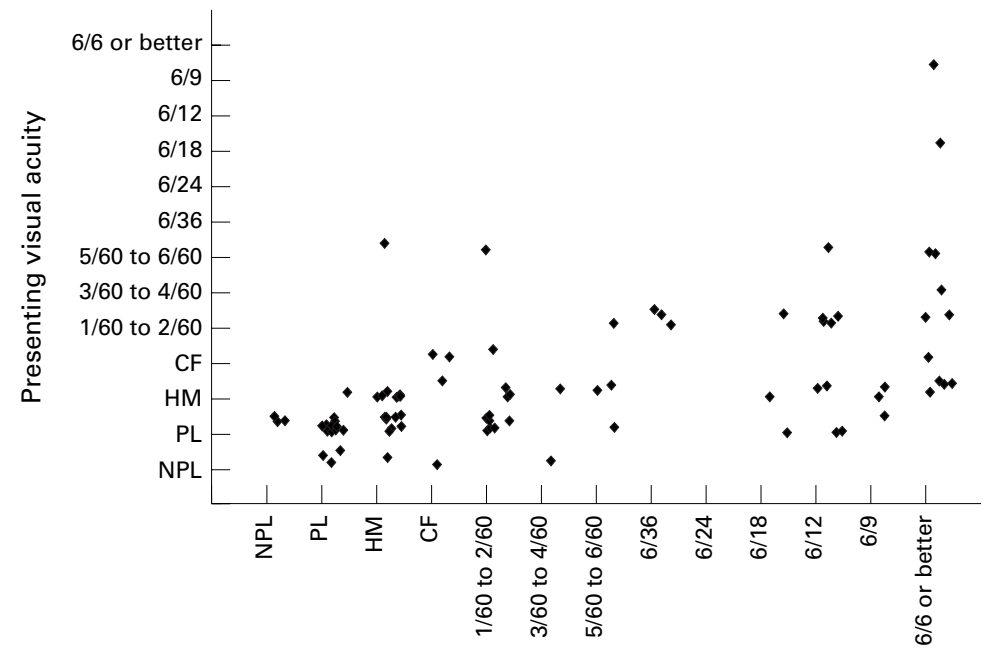

Final visual acuity

Figure 1 Scattergram illustrating the relation between visual outcome and presenting acuity following local intra-arterial fibrinolysis for central retinal artery occlusion. In order to generate a scattergram, categories of Snellen acuity were ascribed an integer score ranging from 1 (NPL) to 13 (6/6 or better). Random noise of not more than plus or minus 0.5 was then superimposed onto the results to ensure that a maximum number of data points were visually represented. $N P L=$ no perception of light, $P L=$ perception of light, $H M=$ hand movements, $C F=$ counting fingers. onset of symptoms and administration of the fibrinolytic agent (simple regression analysis: $r=0.135 ; \mathrm{p}=0.27$ ), or to the type of agent used (ANOVA: $\mathrm{F}=2.54 ; \mathrm{p}=0.11$ ). However, changes in Snellen vision did differ between groups of subjects categorised according to presenting acuities (ANOVA: $\mathrm{F}=3.43 ; \mathrm{p}=0.02$ ). In general, poor initial acuity was a poor prognostic indicator (Fig 1). Seven of 48 eyes (14.6\%) with PL or no perception of light (NPL) at presentation achieved a final Snellen acuity of $6 / 36$ or better, whereas nine of 32 eyes $(28.1 \%)$ with presenting acuities of hand movements (HM) or counting fingers (CF) achieved this level of vision. There is no dramatic change in the results if we include case reports and small series.

Of the 100 patients reported, and accounting for duplication of data, complications were seen in six $(6 \%)$. Complications included haemorrhage at puncture track of femoral artery (one), ${ }^{6}$ hemiplegia with recovery (three), ${ }^{318}$ and hypertensive crisis with recovery (one). ${ }^{18}$ All cases of hemiplegia were treated with immediate fibrinolytic therapy following angiographic identification of the occluded vessel, thus averting a permanent neurological deficit. Of note, no cases of cerebral or retinal bleeding were reported.

\section{Discussion}

The aim of LIF in cases of CRAO is to restore retinal blood supply by dissolving the occluding thromboembolus, and rt-PA has become the agent of choice for this procedure because of its shorter half life and minimal effects on physiological clotting, and because its local administration reduces the risk of systemic side effects. ${ }^{20}$ The rationale of LIF rests on the assumption that the damage caused by retinal ischaemia is reversible. A retinal tolerance time of 105 minutes has been demonstrated in monkeys following total occlusion of the central retinal artery, ${ }^{21}$ and up to 4 hours in the presence of a moderate amount of residual retinal circulation. ${ }^{22}$ In humans, however, significant visual improvement occurring 48 hours or more following conventional treatment for CRAO has been reported in eight of 32 cases reviewed by Augsburger and Magargal, although the visual prognosis was noted to worsen with increasing duration of visual symptoms. ${ }^{23}$ Another concern rests on the fact that only $15.5 \%$ of retinal emboli are composed of platelet fibrin, the remainder being made up of cholesterol $(74.5 \%)$ and calcium $(10.5 \%) .{ }^{24}$ As fibrinolytic agents have no effect on cholesterol or calcium, it has been postulated that LIF may be appropriate for only a minority of patients. ${ }^{22}$ However, it should be noted that the most cases of CRAO are thrombotic and not embolic, and that the stasis induced by non-platelet fibrin emboli can result in the formation of secondary thrombi which contribute to the arterial occlusion. ${ }^{25}$

Of the 16 studies reporting on the use of LIF for CRAO, all are retrospective and nonrandomised, and only two compared the visual outcome of LIF with the natural course of disease in control subjects. ${ }^{35}$ The results of our 
meta-analysis indicate that intra-arterial fibrinolytic therapy in cases of acute CRAO is associated with a marginally better visual outcome than conservative forms of management. For example, a final acuity of $6 / 6$ or better was seen in $14 \%$ of patients following LIF compared with $9 \%$ for the natural course of CRAO, ${ }^{22}$ and a visual result of $6 / 12$ or better was seen in $27 \%$ of subjects compared with $18 \%$ to $21 \%$ reported for a variety of conventional treatments. ${ }^{23}{ }^{26}$ In one of the two controlled studies, a marked improvement in acuity (equals five Snellen lines) was seen in five of 15 patients treated with intra-arterial urokinase $(33 \%)$ but in none of the 17 subjects treated with traditional methods. ${ }^{5}$ However, these findings should be interpreted with full appreciation of the possibility that publication bias may have limited the reporting of unfavourable results.

The questionable rationale of LIF for CRAO, and the inconclusive results of this meta-analysis, are reflected in a lively debate on the subject in a recent issue of Ophthalmology. ${ }^{22}$ Hayreh, in response to the favourable report of Richard et al of LIF in cases of acute occlusion of the central retinal artery ${ }^{18}$ expresses several concerns. In addition to the issues of retinal tolerance time, study design, and embolus composition, Hayreh argues that fundus fluorescein angiography is a "fundamental requirement for any study dealing with a retinal circulatory disorder" in order to establish the amount of residual retinal blood flow before fibrinolysis; the presenting acuity may be deceptively poor because testing is done under less than ideal conditions in an emergency situation, and the patient has not yet learnt to fixate eccentrically; the lack of a relation between visual outcome and time lapse between the occlusive event and administration of fibrinolytic therapy is inconsistent with published scientific studies. ${ }^{27}$ In brief, Hayreh believes the results reported by Richard et al simply represent the natural history of CRAO. ${ }^{22}$

Nevertheless, CRAO remains a visually debilitating condition for which we have no effective treatment. If LIF was to result in even a marginally better visual outcome than conventional management, it would be a welcome advance. It is likely that a substantial proportion of patients would consent to undergo this emergency procedure as a recent survey has shown that $37 \%$ of binocular adults with CRAO would risk a cerebrovascular accident or death in order to triple their chances of recovering a visual acuity of $6 / 36$ or better in one eye, and this rose to $80 \%$ for monocular subjects. ${ }^{28}$

We need and should support a randomised controlled trial (RCT) of LIF for CRAO if the debate regarding the risks and benefits of this procedure is to be brought to a satisfactory conclusion. In our view, there is currently insufficient evidence to justify LIF outside of a RCT.

1 Karjalainen $\mathrm{K}$. Occlusion of the central retinal artery and retinal branch arterioles. Acta Ophthalmol 1971;109 (Suppl): 1-96.

2 Atebara NH, Brown GC, Cater J. Efficacy of anterior chamber paracentesis and carbogen in treating acute nonarteritic central retinal artery occlusion. Ophthalmology 1995;102: 2029-35.

3 Schmidt D, Schumacher M, Wakhloo AK. Microcatheter urokinase infusion in central retinal artery occlusion. $A m \mathcal{F}$ Ophthalmol 1992;113:429-34.

$4 \mathrm{Ma} \mathrm{Z,} \mathrm{Li} \mathrm{B,} \mathrm{Dou} \mathrm{H.} \mathrm{Treatment} \mathrm{of} \mathrm{central} \mathrm{retinal} \mathrm{artery}$ occlusion with thrombolysis via superselective ophthalmic artery catheterization. Chin 7 Ophthalmol 1996;32:445-7.

5 Weber J, Remonda L, Mattle HP, et al. Selective intraarterial fibrinolysis of acute central retinal artery occlusion. Stroke 1998;29:2076-9.

6 Schumacher M, Schmidt D, Wakhloo AK. Intra-arterial fibrinolytic therapy in central retinal artery occlusion. Neuroradiology 1993;35:600-5.

7 Annonier P, Benichou CL, Flament J, et al. Place de la fibrinolyse dans le traitement des obliterations arterielles retiniennes. Discussion de cinq observations. Bull Soc Ophtalmol Fr 1988;10:1167-71.

8 Schumacher M, Schmidt D, Wakhloo AK. Intraarterielle Fibrinolyse bei Zentralarterienverschluss. Radiologe 1991; 31:240-3.

9 Vulpius $\mathrm{K}$, Hoh $\mathrm{H}$, Lange $\mathrm{H}$, et al. Seletive perkutane transluminale Lysetherapie mit RTPA bei retinalem Zentralarterienverschluss. Ophthalmologe 1996;93:149-53.

10 Annonier P, Sahel J, Wenger JJ, et al. Traitement fibrinolytique local dans les occlusions de l'artere centrale de la retine. f Fr Ophtalmol 1984;7:711-6.

11 Van Cauwenberge F. Fibrinolyse: indications en ophtalmologie. Bull Soc Belge Ophtalmol 1993;247:71-3.

12 Coscas MMG, Samama J, Perles C. Obliteration de l'A CR et streptokinase. Bull Soc Ophtalmol Fr 1970;70:59-62.

13 Turmer KH, Guhl A, Hettesheimer H, et al. Technik der selektiven kontrollierten retinalen Fibrinolyse im Modell. Ophtalmologe 1993;90:472-5.

14 Brassel F. Moglichkeiten und Grenzen der lokalen intraarteriellen Fibrinolyse (LIF) bei thromboembolischen Gefassverschlussen im ZNS. Innere Medizin 1993;48:351-5.

15 Wirostko WJ, Pulido JS, Hendrix LE. Selective thrombolysis of central retinal artery occlusion without long-term systemic heparinization. Surg Neurol 1998;50:408-10.

16 Weill A, Cognard C, Piotin M, et al. Persistent value of intra-arterial fibrinolysis 8 hours or more following central retinal artery occlusion or of its branches. $\mathcal{F}$ Fr d'Ophtalmol 1998;21:466-70.

17 Mach R, Kessler P, Susicky P, et al. Trombolyza arterialni sitnicove okluse urokinazou. Ceskoslovenska Oftalmologie 1992;48:42-8.

18 Richard G, Lerche R-C, Knospe V, et al. Treatment of retinal arterial occlusion with local fibrinolysis using recombinant tissue plasminogen activator. Ophthalmology 1999; 106: $768-73$

19 Tramer MR, Reynolds JM, Moore RA, et al. Impact of covert duplicate publication on meta-analysis: a case study. BMF 1997;315:635-40

20 Bertram B, Wolf S, Fisches H, et al. Thrombolytic treatment of retinal arterial occlusions with plasminogen activator. Klin Monatsbl Augenklinik 1991;198:295-300.

21 Hayreh SS, Kolder HE, Weingeist TA. Central retinal artery occlusion and retinal tolerance time. Ophthalmology 1980; 87:75-8.

22 Hayreh SS. Retinal arterial occlusion with LIF using rTPA. Ophthalmology 1999;106:1236-8.

23 Augsburger JJ, Magargal LE. Visual prognosis following treatment of acute central retinal artery obstruction. $B r f$ treatment of acute central reti

24 Arruga J, Sanders MD. Ophthalmologic findings in 70 patients with with evidence of retinal embolism. Ophthalmology 1982;89:1336-7.

25 Castaigne P, Lhermitte F, Gautier JC, et al. Internal carotid artery occlusion. A study of 61 instances in 50 patients with post-mortem data. Brain 1970;93:231-58.

26 Brown GC, Magargal LE. Central retinal artery obstruction and visual acuity. Ophthalmology 1982;89:14-9.

27 Szabo ME, Droy-Lefaix MT, Doly M, et al. Ischaemia and reperfusion-induced histologic changes in the rat retina. Deomnstration of a free radical-mediated mechanism. Invest Ophthalmol Vis Sci 1991;32:1471-8.

28 Margo CE, Mack WP. Therapeutic decisions involving disparate clinical outcomes. Patient preference survey for treatment of central retinal artery occlusion. Ophthalmology 1996;103:691-6. 